\title{
Detection and genetic characterization of Giardia duodenalis in pigs from large-scale farms in Xinjiang, China
}

\author{
Bo Jing ${ }^{1}$, Ying Zhang ${ }^{1}$, Chunyan $\mathrm{Xu}^{1}$, Dongfang $\mathrm{Li}^{2}$, Jinming Xing ${ }^{1}$, Dayong Tao ${ }^{1}$, Longxian Zhang ${ }^{2}$, Meng $\mathrm{Qi}^{1 \text {,** }}$ \\ and Haiyan Wang ${ }^{3, *}$ \\ ${ }^{1}$ College of Animal Science, Tarim University, Alar, 843300 Xinjiang, PR China \\ ${ }^{2}$ College of Animal Science and Veterinary Medicine, Henan Agricultural University, Zhengzhou, 450046 Henan, PR China \\ ${ }^{3}$ Experimental and Research Center, Henan University of Animal Husbandry and Economy, Zhengzhou, 450046 Henan, PR China
}

Received 8 May 2019, Accepted 14 August 2019, Published online 26 August 2019

\begin{abstract}
To study the presence of Giardia duodenalis in Xinjiang, northwest China, we collected 801 fecal specimens from seven large-scale pig farms and screened them using PCR targeting the SSU rRNA gene. Twenty-one (2.6\%) of the specimens from five farms were $G$. duodenalis-positive, with a significant difference in prevalence among different farms $(0-8.7 \%)(p<0.01)$. Giardia duodenalis prevalence was highest in fattening pigs $(5.4 \%$, $7 / 129)$, followed by sows $(3.2 \%, 7 / 222)$, post-weaning piglets $(1.8 \%, 5 / 281)$, and pre-weaning piglets $(1.2 \%$, $2 / 169)$, but there was no significant difference in prevalence among the age groups $(p>0.05)$. Sequence analysis of the SSU rRNA gene revealed that the $21 \mathrm{G}$. duodenalis strains belonged to three assemblages: A $(n=2)$, $\mathrm{B}(n=16)$, and $\mathrm{E}(n=3)$. Assemblage $\mathrm{B}$ was the predominant assemblage and was widely distributed in all $G$. duodenalis-positive farms and age groups. All $G$. duodenalis-positive specimens were further assayed at the $\beta$-giardin $(b g)$, glutamate dehydrogenase $(g d h)$, and triosephosphate isomerase (tpi) genes, and two tpi, four $g d h$, and two $b g$ sequences were identified. These data indicate that pigs may be a zoonotic risk and can potentially spread G. duodenalis infection from animals to humans.
\end{abstract}

Key words: Giardia duodenalis, Prevalence, PCR, Assemblages, Zoonoses.

Résumé - Détection et caractérisation génétique de Giardia duodenalis chez des porcs de grandes exploitations du Xinjiang, en Chine. Afin d'étudier la présence de Giardia duodenalis dans le Xinjiang, dans le nord-ouest de la Chine, nous avons collecté 801 échantillons de selles de sept grandes exploitations porcines et les avons analysés à l'aide d'une PCR ciblant le gène SSU de l'ARNr. Vingt-et-un $(2,6 \%)$ des spécimens provenant de cinq exploitations étaient positifs pour G. duodenalis, avec une différence de prévalence significative entre les différentes exploitations $(0 \%$ à $8,7 \%)(p<0,01)$. La prévalence de Giardia duodenalis était la plus élevée chez les porcs d'engraissement $(5,4 \%, 7 / 129)$, suivie des truies $(3,2 \%, 7 / 222)$, des porcelets en post-sevrage $(1,8 \%$, $5 / 281)$ et des porcelets en pré-sevrage $(1,2 \%, 2 / 169)$, mais il n'y avait pas de différence significative dans la prévalence entre les groupes d'âge $(p>0,05)$. L'analyse de la séquence du gène SSU de l'ARNr a révélé que les 21 souches de $G$. duodenalis appartenaient à trois assemblages : A $(n=2), \mathrm{B}(n=16)$ et $\mathrm{E}(n=3)$. L'assemblage B était l'assemblage prédominant et était largement distribué dans toutes les fermes et groupes d'âge positifs pour G. duodenalis. Tous les échantillons positifs pour $G$. duodenalis ont ensuite été analysés pour les gènes $\beta$-giardine $(b g)$, glutamate déshydrogénase $(g d h)$ et triosephosphate isomérase (tpi), et deux séquences de tpi, quatre de $g d h$ et deux de $b g$ ont été identifiées. Ces données indiquent que les porcs peuvent présenter un risque zoonotique et potentiellement transmettre l'infection à G. duodenalis des animaux à l'homme.

\section{Introduction}

Giardia duodenalis is a common protozoan parasite that can infect humans, livestock, companion animals, and wildlife

\footnotetext{
*Corresponding author: qimengdz@163. com;
} 1115110106@qq.com
[7]. G. duodenalis is considered a complex species and has been grouped into eight distinct assemblages or genotypes (A-H) based on genetic analysis. Among them, assemblages $\mathrm{A}$ and $\mathrm{B}$ have a wide host range and are responsible for the majority of known human disease cases [8], while assemblages $\mathrm{C}-\mathrm{H}$ seem to be host-specific for nonhuman species (canids, domestic mammals, cats, rodents, and seals) [7]. In

This is an Open Access article distributed under the terms of the Creative Commons Attribution License (http://creativecommons.org/licenses/by/4.0), which permits unrestricted use, distribution, and reproduction in any medium, provided the original work is properly cited. 
pigs, assemblage $\mathrm{E}$ is the predominant genotype in most countries, but the zoonotic assemblages $\mathrm{A}$ and $\mathrm{B}$ have also been detected in pigs, suggesting that pigs may be a reservoir for giardiasis $[3,10,13,20,21]$.

To date, $G$. duodenalis infection has been frequently reported in a wide range of animals in China, including cattle $(1.7-74.2 \%)$, sheep $(0-13.1 \%)$, goats $(0-27.78 \%)$, rabbits (3.9-8.3\%) and other mammals (donkeys, golden takins, raccoon dogs, and horses) [11]. Although the pig industry and pig husbandry play important roles in China, few reports of G. duodenalis infection in pigs in China are available. In the published studies, assemblages $\mathrm{A}$ and $\mathrm{E}$ were identified in pigs, with assemblage $\mathrm{E}$ being the predominant assemblage [12, 20, 21]. Here, we examine the prevalence and assemblage distribution of $G$. duodenalis in pigs in the Xinjiang Uygur Autonomous Region (hereafter referred to as Xinjiang), northwest China, to assess zoonotic transmission risk and elucidate the public health significance of this protozoan parasite.

\section{Materials and methods}

\section{Specimen collection}

A total of 801 fresh fecal specimens were collected from 169 pre-weaning piglets (<20 days old), 281 post-weaning piglets (21-70 days old), 129 fattening pigs (71-180 days old), and 222 sows (>181 days old) from seven large-scale pigs farms in Marabishi, Alaer, Yarkant, Baicheng, Shaya, Changji, and Ruoqiang in Xinjiang between September 2017 and June 2018. Each of the sampled farms ranged from 10,000 to 80,000 pigs. These farms were visited on a single occasion and specimens were randomly collected from the animals by a veterinarian. At the time of collection, no diarrhea was apparent in the herds. Using sterile gloves, specimens were collected directly from the rectum or immediately from fresh feces deposited on the ground after animal defecation. The fresh feces were placed into clean plastic bags marked with the date, age, and farm, and immediately placed onto ice packs in an insulated container. Specimens were transported to the laboratory, stored at $4{ }^{\circ} \mathrm{C}$, and processed no later than a week after collection.

\section{DNA extraction and PCR amplification}

Genomic DNA was extracted from approximately $200 \mathrm{mg}$ of each fecal specimen using the E.Z.N.A.R ${ }^{\circledR}$ Stool DNA Kit (D4015-02, Omega Bio-Tek Inc., Norcross, GA, USA), according to the manufacturer's instructions. Extracted DNA specimens were used as a template for polymerase chain reaction (PCR)-based analyses. Positive (dairy cattle-derived assemblage E DNA) and negative controls (distilled water) were included in each PCR assay.

G. duodenalis was identified using the SSU rRNA gene, as described previously [2] (Table 1). PCR reactions were conducted in $25 \mu \mathrm{L}$ reaction mixtures consisting of $2.5 \mu \mathrm{L}$ $1 \times$ PCR buffer (TaKaRa Shuzo Co. Ltd., Otsu, Japan), $2 \mu \mathrm{L}$ $200 \mu \mathrm{M}$ dNTP mixture (TaKaRa Shuzo Co. Ltd., Otsu, Japan), $0.15 \mu \mathrm{L}$ of TaKaRa rTaq (TaKaRa Shuzo Co. Ltd., Otsu, Japan), $1.25 \mu \mathrm{L}$ dimethyl sulfoxide (DMSO), $0.3 \mu \mathrm{M}$ forward and reverse primer, $1 \mu \mathrm{L}$ genomic DNA, and $17.5 \mu \mathrm{L}$ double-distilled water. Each specimen was processed twice at the SSU rRNA gene.

DNA from all SSU rRNA-positive specimens was further tested using PCRs targeting the $\beta$-giardin $(b g)$, glutamate dehydrogenase $(g d h)$, and triosephosphate isomerase (tpi) genes, as described previously $[5,9,19]$ (Table 1 ). PCR reactions were conducted in $25 \mu \mathrm{L}$ reaction mixtures consisting of $2.5 \mu \mathrm{L}$ $1 \times$ PCR buffer (TaKaRa Shuzo Co. Ltd., Otsu, Japan), $2 \mu \mathrm{L}$ $200 \mu \mathrm{M}$ dNTP mixture (TaKaRa Shuzo Co. Ltd., Otsu, Japan), $0.15 \mu \mathrm{L}$ of TaKaRa Ex Taq (TaKaRa Shuzo Co. Ltd., Otsu, Japan), $0.3 \mu \mathrm{M}$ forward and reverse primer, $1 \mu \mathrm{L}$ genomic DNA, and $18.75 \mu \mathrm{L}$ double-distilled water. Each specimen was processed at least three times at the $b g, g d h$ and $t p i$ genes.

\section{Sequence analysis}

PCR amplicons of the correct size were DNA sequenced by GENEWIZ (Suzhou, China). Sequence accuracy was confirmed by bidirectional sequencing. The resulting sequences were aligned against reference sequences downloaded from the National Center for Biotechnology Information GenBank database (https://www.ncbi.nlm.nih.gov/) using the ClustalX 2.1 program to determine the assemblages of $G$. duodenalis in each specimen.

All nucleotide sequences of the SSU rRNA, $b g, g d h$, and tpi genes of $G$. duodenalis isolated from pigs in this study were deposited in the GenBank database under accession numbers: MK881597 - MK881599, MK881600 - MK881601, MK881602 - MK881605, and MK881606 - MK881607, respectively.

\section{Statistical analysis}

Differences in prevalence between ages and farms were compared with the $\chi^{2}$ test in SPSS for Windows (Release 13.0 standard version; SPSS Inc., Chicago, IL, USA). Differences of $p<0.05$ were considered significant.

\section{Results}

Of the 801 fecal specimens collected from seven farms, 21 animals $(2.6 \%, 21 / 801)$ from five farms tested positive for G. duodenalis based on the SSU rRNA gene. The prevalence in pigs in this study is within the range reported in previous studies. The highest prevalence was observed in a farm from Ruoqiang $(8.7 \%, 13 / 149)$, followed by Baicheng $(5.1 \%, 5 / 99)$, Shaya $(1.0 \%, 1 / 100)$, Yarkant $(0.8 \%, 1 / 130)$, and Changji $(0.8 \%, 1 / 130)$. G. duodenalis was not detected in specimens from farms in Alaer and Marabishi. The prevalence of G. duodenalis in pigs was significantly different among different farms $\left(\chi^{2}=27.952, d f=5, p<0.01\right)$ (Table 2). The prevalence of $G$. duodenalis in fattening pigs was $5.4 \%$ (7/129), higher than sows $(3.2 \%, 7 / 222)$, post-weaning piglets $(1.8 \%, 5 / 281)$, and pre-weaning piglets $(1.2 \%, 2 / 169)$, but the differences between age groups were not significant $\left(\chi^{2}=6.371, d f=3, p>0.05\right)$ (Table 3).

Based on the molecular analysis of the SSU rRNA gene, three assemblages, $\mathrm{A}(n=2), \mathrm{B}(n=16)$, and $\mathrm{E}(n=3)$, were 
Table 1. The primers used in the characterization of G. duodenalis in the present study.

\begin{tabular}{|c|c|c|c|c|c|}
\hline Gene & Primer sequence $\left(5^{\prime}-3^{\prime}\right)$ & $\begin{array}{c}\text { Fragment } \\
\text { length } \\
\text { (bp) }\end{array}$ & $\begin{array}{c}\text { Annealing } \\
\text { temperature } \\
\left({ }^{\circ} \mathrm{C}\right)\end{array}$ & Usage (s) & References \\
\hline \multirow{4}{*}{$\begin{array}{l}\text { SSU } \\
\text { rRNA }\end{array}$} & Gia2029: AAGTGTGGTGCAGACGGACTC & $\sim 497$ & 55 & \multirow{4}{*}{$\begin{array}{l}\text { Specific nested PCR of } \\
\text { G. duodenalis }\end{array}$} & \multirow[t]{4}{*}{ [2] } \\
\hline & Gia2150c: CTGCTGCCGTCCTTGGATGT & & & & \\
\hline & RH11: CATCCGGTCGATCCTGCC & 292 & 59 & & \\
\hline & RH4: AGTCGAACCCTGATTCTCCGCCCAGG & & & & \\
\hline \multirow[t]{4}{*}{$b g$} & G7: AAGCCCGACGACCTCACCCGCAGTGC & $\sim 753$ & 65 & \multirow[t]{4}{*}{ Genotyping of $G$. duodenalis } & \multirow[t]{4}{*}{ [9] } \\
\hline & G759: GAGGCCGCCCTGGATCTTCGAGACGAC & & & & \\
\hline & Forward: GAACGAGATCGAGGTCCG & $\sim 511$ & 55 & & \\
\hline & Reverse: CTCGACGAGCTTCGTGTT & & & & \\
\hline \multirow[t]{4}{*}{$g d h$} & Ghd1: TTCCGTRTYCAGTACAACTC & $\sim 530$ & 50 & \multirow[t]{4}{*}{ Genotyping of $G$. duodenalis } & \multirow[t]{4}{*}{ [5] } \\
\hline & Gdh2: ACCTCGTTCTGRGTGGCGCA & & & & \\
\hline & Gdh3: ATGACYGAGCTYCAGAGGCACGT & & 50 & & \\
\hline & Gdh4: GTGGCGCARGGCATGATGCA & & & & \\
\hline \multirow[t]{4}{*}{ tpi } & AL3543: AAATIATGCCTGCTCGTCG) & $\sim 605$ & 50 & \multirow[t]{4}{*}{ Genotyping of $G$. duodenalis } & \multirow[t]{4}{*}{ [19] } \\
\hline & AL3546: CAAACCTTITCCGCAAACC) & & & & \\
\hline & AL3544: CCCTTCATCGGIGGTAACTT) & $\sim 530$ & 50 & & \\
\hline & AL3545: GTGGCCACCACICCCGTGCC) & & & & \\
\hline
\end{tabular}

Table 2. The prevalence and assemblages of Giardia duodenalis in pigs from the seven large-scale farms in Xinjiang, China.

\begin{tabular}{lccc}
\hline Collection site & No. specimens & No. positive (\%) & Assemblage (no.) \\
\hline Marabishi & 98 & 0 & - \\
Alaer & 95 & 0 & - \\
Yarkant & 130 & $1(0.8)$ & B (1) \\
Baicheng & 99 & $5(5.1)$ & A (2), B (1), E (2) \\
Shaya & 100 & $1(1.0)$ & E (1) \\
Changji & 130 & $1(0.8)$ & B (1) \\
Ruoqiang & 149 & $13(8.7)$ & B (13) \\
Total & 801 & $21(2.6)$ & A (2), B (16), E (3) \\
\hline
\end{tabular}

Table 3. The prevalence and assemblages of Giardia duodenalis in pigs of different ages in Xinjiang, China.

\begin{tabular}{lccc}
\hline Age (days) & No. specimens & No. positive (\%) & Assemblage (no.) \\
\hline Pre-weaning piglets (<20 days) & 169 & $2(1.2)$ & B (2) \\
Post-weaning piglets $(21-70$ days) & 281 & $5(1.8)$ & A (2), B (3) \\
Fattening pigs ( $71-180$ days) & 129 & $7(5.4)$ & B (4), E (3) \\
Sows (>181 days) & 222 & $7(3.2)$ & B (7) \\
\hline
\end{tabular}

detected among 21 G. duodenalis-positive specimens (Table 2). The 21 SSU rRNA-positive G. duodenalis specimens were further characterized based on the $t p i, g d h$, and $b g$ genes, generating two, four, and two sequences, respectively (Table S1). Of two tpi sequences, one was identified as assemblage $\mathrm{B}$ and the other was identified as assemblage E (Table S1). The assemblage B sequence was identical to the sub-assemblage BII sequence (GenBank accession no. KX468987) from humans in Spain, while assemblage $\mathrm{E}$ was identified as a novel sequence and showed $99 \%$ similarity to the assemblage $\mathrm{E}$ sequence (KJ668134) from pigs in China. The four $g d h$ sequences obtained in this study were identified as assemblages $\mathrm{A}(n=1), \mathrm{B}(n=1), \mathrm{E} 1(n=1)$ and E2 $(n=1)$ (Table S1). Assemblage A and B sequences were identical to the subassemblage AII sequence (EF507661) from humans in Brazil and the assemblage B sequence from chinchillas in China, respectively. Assemblage E1 and E2 sequences were identical to the assemblage E sequence (KJ668145) from a pig in China and assemblage E sequence (MG820464) from cattle in USA, respectively. Of two $b g$ sequences, one was identified as a novel sequence of assemblage B, showing $99 \%$ similarity to the assemblage B sequence (LC436571) from humans in Japan, while the other was identified as assemblage $\mathrm{E}$ and was identical to the assemblage E sequence (KU668892) from wild boars in China.

Based on multilocus genotyping analysis, only two fecal specimens of assemblage E and assemblage B were successfully sequenced at all three genes, forming one novel assemblage B MLG and one novel assemblage E MLG (Table S1).

\section{Discussion}

Varying prevalence of $G$. duodenalis has been reported in pigs worldwide, ranging from $0 \%$ in pigs from Preah Vihear, Cambodia (0/74), to $66.4 \%(81 / 122)$ in pigs from Ontario, Canada $[6,16]$. In China, the prevalence of $G$. duodenalis in domestic pigs was $1.7 \%$ (15/897) from Henan Province, 
Table 4. Global distribution of assemblages of Giardia duodenalis in pigs.

\begin{tabular}{|c|c|c|c|c|c|c|c|c|c|c|}
\hline \multirow[t]{2}{*}{ Location } & \multirow[t]{2}{*}{ Host } & \multirow[t]{2}{*}{ No. specimens genotyped } & \multirow[t]{2}{*}{ Genes } & \multicolumn{6}{|c|}{$\begin{array}{c}\text { No. of specimens with } \\
\text { assemblage }\end{array}$} & \multirow[t]{2}{*}{ References } \\
\hline & & & & $\mathrm{A}$ & $\mathrm{B}$ & $\mathrm{C}$ & $\mathrm{D}$ & $\mathrm{E}$ & $\mathrm{F}$ & \\
\hline Denmark & Domestic pig & 82 & SSU rRNA and $g d h$ & 10 & & & 1 & 71 & & {$[10]$} \\
\hline Denmark & Domestic pig & 13 & SSU rRNA and $g d h$ & 2 & & & & 11 & & [14] \\
\hline Italy & Domestic pig & 1 & $b g, t p i$ and $g d h$ & 1 & & & & & & [5] \\
\hline Australia & Domestic pig & $55^{\mathrm{a}}$ & SSU rRNA & 19 & & & & 37 & 1 & {$[3]$} \\
\hline Canada & Domestic pig & 81 & SSU rRNA and $b g$ & & 75 & & & 6 & & {$[6]$} \\
\hline UK & Domestic pig & 3 & SSU rRNA & & & 1 & & 2 & & {$[13]$} \\
\hline Poland & Domestic pig & 5 & bg & & 1 & & & 4 & & {$[18]$} \\
\hline USA & Domestic pig & 3 & $b g, g d h$ and $t p i$ & 2 & & & & 1 & & [15] \\
\hline China & Domestic pig & 45 & $b g, g d h$ and $t p i$ & 9 & & & & 36 & & [20] \\
\hline China & Domestic pig & 15 & tpi & 3 & & 3 & & 9 & & {$[21]$} \\
\hline Nigeria & Domestic pig & $53^{\mathrm{b}}$ & SSU rRNA and $g d h$ & & 16 & & & 39 & & [1] \\
\hline China & Domestic pig & 21 & SSU rRNA, $b g, g d h$ and $t p i$ & 2 & 16 & & & 3 & & This study \\
\hline Croatia & Wild boar & 1 & SSU rRNA, ITS and tpi & 1 & & & & & & [4] \\
\hline China & Wild boar & 11 & bg & 2 & & & & 9 & & {$[12]$} \\
\hline Total & & 389 & SSU rRNA, $b g, g d h$, ITS and $t p i$ & 51 & 108 & 4 & 1 & 228 & 1 & \\
\hline
\end{tabular}

${ }^{\text {a }}$ Mixed infection with both assemblages $\mathrm{A}$ and $\mathrm{E}$ in two isolates.

${ }^{\mathrm{b}}$ Mixed infection with both assemblages $\mathrm{B}$ and $\mathrm{E}$ in two isolates.

$8.0 \%(45 / 560)$ from Shaanxi Province in domestic pigs, and $3.1 \%(11 / 357)$ from Sichuan Province in captive Eurasian wild boars $[12,20,21]$. In this study, $2.6 \%$ of 801 pigs were found to be infected with $G$. duodenalis. The discrepancy between previous studies was potentially due to farm hygiene management, including differences in animals stocking density, hygiene regimes, or water supply [20]. To prevent this potential issue, all pigs used in this study were from intensive breeding farms and fed using underground water. An alternative possible explanation for the transmission of $G$. duodenalis cysts is by vectors such as flies and rodents, which could be explored in future studies.

A previous study in Denmark found that the highest $G$. duodenalis prevalence was in post-weaning pigs $(20-30 \mathrm{~kg})(27.4 \%, 64 / 234)$, and the lowest was in the piglets (<7 weeks) $(2.0 \%, 3 / 152)$ [14]. Similarly, a study in Australia found the highest $G$. duodenalis prevalence in post-weaning pigs (4 weeks to 6 months) $(41.0 \%, 64 / 156)$, and the lowest in pre-piglets (11 days to 3 weeks) $(18.7 \%, 23 / 123)$ [3]. In contrast, a study in Zambia found the highest $G$. duodenalis prevalence in sows $(40.0 \%, 6 / 15)$, and the lowest in pre-piglets (2-5 weeks) $(6.3 \%, 2 / 32)$ [17], and a study in Shaanxi Province, China found the highest prevalence in sows $(10.5 \%, 6 / 57)$ and the lowest in boars $(3.3 \%, 1 / 30)$ [20]. In this study, the highest $G$. duodenalis prevalence was in fattening pigs (70-180 days) $(5.4 \%, 7 / 129)$, and the lowest was in preweaning piglets $(<20$ days $)(1.2 \%, 2 / 169)$. Because of the absence of uniform age divisions and the different sample sizes across studies, it is difficult to evaluate the association between pig age and $G$. duodenalis infection; more studies should be undertaken to illustrate this association.

To date, six G. duodenalis assemblages (A-F) have been reported in pigs, with assemblage $\mathrm{E}$ being the predominant assemblage (Table 4). Among these assemblages, A, B, and $\mathrm{E}$ have been detected in humans. In this study, the zoonotic assemblage B was the predominant assemblage (76.0\%, $16 / 21$ ) and was widely distributed in all tested farms and age groups, while assemblage $\mathrm{E}$ was only found in three fattening pigs (Table 2). These results were consistent with a study from Ontario, Canada, where DNA sequencing detected 63 G. duodenalis-positive swine samples, $92.1 \%$ of which were assemblage B and $7.9 \%$ were assemblage E [6]. Previous studies in Australia [3], Denmark [10, 14], and China [20, 21], however, found that assemblage E was predominant.

Genes $b g, g d h$, and tpi were used to determine the subassemblage of $G$. duodenalis. In this study, sub-assemblage AII and BII was identified at the genes $g d h$ and tpi, respectively, which has previously been reported in humans, livestock, and companion animals worldwide [5, 7, 11]. These results reveal that pigs may play a role in human giardiasis infections. In contrast, the sub-assemblage $\mathrm{E}$ in this study has previously been reported in cattle, sheep and pigs.

To further clarify the genetic diversity of $G$. duodenalis in pigs, we found only one novel assemblage B MLG and one novel assemblage E MLG (Table S1), which were genetically different from previous samples from northwestern China [20]. Because there is little data on MLGs in pigs worldwide, we cannot determine the characteristics of $G$. duodenalis in pigs (such as geographic or host segregation), thus further epidemiological surveys should be undertaken to analyze the genetic differences.

\section{Conclusion}

Although a low prevalence of $G$. duodenalis infection $(2.6 \%, 21 / 801)$ was identified in this study, the identification of zoonotic assemblages $\mathrm{A}, \mathrm{B}$, and $\mathrm{E}$, and the predominance of assemblage B, suggest that pigs pose a potential risk for the zoonotic transfer of $G$. duodenalis in the studied region. 


\section{Competing interests}

The authors declare that they have no competing interests.

Acknowledgements. This study was supported in part by the National Natural Science Foundation of China (3180218, 31702227), the open fund of Key Laboratory of livestock Disease Prevention of Guangdong Province (YDWS1704), and the Program for Young and Middle-aged Leading Science, Technology, and Innovation of Xinjiang Production \& Construction Group (2018CB034). The sponsors had no role in study design, in the collection, analysis, or interpretation of data, in the writing of the report, or in the decision to submit the article for publication.

\section{Supplementary material}

Supplementary material is available at https://www.parasite-journal.org/10.1051/parasite/2019056/olm

\section{References}

1. Akinkuotu OA, Takeet MI, Otesile EB, Olufemi F, Greenwood SJ, McClure JT. 2019. Prevalence and multilocus genotypes of Giardia duodenalis infecting pigs in Ogun state, Nigeria. Infection, Genetics and Evolution, 70, 53-60.

2. Appelbee AJ, Frederick LM, Heitman TL, Olson ME. 2003. Prevalence and genotyping of Giardia duodenalis from beef calves in Alberta, Canada. Veterinary Parasitology, 112, 289-294.

3. Armson A, Yang R, Thompson J, Johnson J, Reid S, Ryan UM. 2009. Giardia genotypes in pigs in Western Australia: prevalence and association with diarrhea. Experimental Parasitology, 121, 381-383.

4. Beck R, Sprong H, Lucinger S, Pozio E, Cacciò SM. 2010. A large survey of Croatian wild mammals for Giardia duodenalis reveals a low prevalence and limited zoonotic potential. Vector Borne and Zoonotic Diseases, 11, 1049-1055.

5. Cacciò SM, Beck R, Lalle M, Marinculic A, Pozio E. 2008. Multilocus genotyping of Giardia duodenalis reveals striking differences between assemblages A and B. International Journal for Parasitology, 38, 1523-1531.

6. Farzan A, Parrington L, Coklin T, Cook A, Pintar K, Pollari F, Friendship R, Farber J, Dixon B. 2011. Detection and characterization of Giardia duodenalis and Cryptosporidium spp. on swine farms in Ontario, Canada. Foodborne Pathogens and Disease, 8, 1207-1213.

7. Feng Y, Xiao L. 2011. Zoonotic potential and molecular epidemiology of Giardia species and giardiasis. Clinical Microbiology Reviews, 24, 110-140.

8. Heyworth MF. 2016. Giardia duodenalis genetic assemblages and hosts. Parasite, 23, 13.

9. Lalle M, Pozio E, Capelli G, Bruschi F, Crotti D, Cacciò SM. 2005. Genetic heterogeneity at the beta-giardin locus among human and animal isolates of Giardia duodenalis and identification of potentially zoonotic subgenotypes. International Journal for Parasitology, 35, 207-213.

10. Langkjaer RB, Vigre H, Enemark HL, Maddox-Hyttel C. 2007. Molecular and phylogenetic characterization of Cryptosporidium and Giardia from pigs and cattle in Denmark. Parasitology, 134, 339-350.

11. Li J, Wang H, Wang R, Zhang L. 2017. Giardia duodenalis infections in humans and other animals in China. Frontiers in Microbiology, 8, 2004.

12. Li W, Deng L, Wu K, Huang X, Song Y, Su H, Hu Y, Fu H, Zhong Z, Peng G. 2017. Presence of zoonotic Cryptosporidium scrofarum, Giardia duodenalis assemblage A and Enterocytozoon bieneusi genotypes in captive Eurasian wild boars (Sus scrofa) in China: potential for zoonotic transmission. Parasites \& Vectors, 10, 10.

13. Minetti C, Taweenan W, Hogg R, Featherstone C, Randle N, Latham SM, Wastling JM. 2014. Occurrence and diversity of Giardia duodenalis assemblages in livestock in the UK. Transboundary and Emerging Diseases, 61, e60-e67.

14. Petersen HH, Jianmin W, Katakam KK, Mejer H, Thamsborg SM, Dalsgaard A, Olsen A, Enemark HL. 2015. Cryptosporidium and Giardia in Danish organic pig farms: Seasonal and agerelated variation in prevalence, infection intensity and species/ genotypes. Veterinary Parasitology, 214, 29-39.

15. Rodriguez-Rivera LD, Cummings KJ, McNeely I, Suchodolski JS, Scorza AV, Lappin MR, Mesenbrink BT, Leland BR, Bodenchuk MJ. 2016. Prevalence and diversity of Cryptosporidium and Giardia identified among feral pigs in Texas. Vector Borne and Zoonotic Diseases, 16, 765-768.

16. Schär $F$, Inpankaew $T$, Traub RJ, Khieu V, Dalsgaard A, Chimnoi W, Chhoun C, Sok D, Marti H, Muth S, Odermatt P. 2014. The prevalence and diversity of intestinal parasitic infections in humans and domestic animals in a rural Cambodian village. Parasitology International, 63, 597-603.

17. Siwila J, Mwape KE. 2012. Prevalence of Cryptosporidium spp. and Giardia duodenalis in pigs in Lusaka, Zambia. Onderstepoort Journal of Veterinary Research, 79, E1-E5.

18. Stojecki K, Sroka J, Cencek T, Dutkiewicz J. 2015. Epidemiological survey in Lęczyńsko-Włodawskie Lake District of eastern Poland reveals new evidence of zoonotic potential of Giardia intestinalis. Annals of Agricultural and Environmental Medicine, 22, 594-598.

19. Sulaiman IM, Fayer R, Bern C, Gilman RH, Trout JM, Schantz PM, Das P, Lal AA, Xiao L. 2003. Triosephosphate isomerase gene characterization and potential zoonotic transmission of Giardia duodenalis. Emerging Infectious Diseases, 9, 1444-1452.

20. Wang SS, Yuan YJ, Yin YL, Hu RS, Song JK, Zhao GH. 2017. Prevalence and multilocus genotyping of Giardia duodenalis in pigs of Shaanxi Province, northwestern China. Parasites \& Vectors, 10, 490.

21. Wang H, Zhang Y, Wu Y, Li J, Qi M, Li T, Wang J, Wang R, Zhang S, Jian F, Ning C, Zhang L. 2018. Occurrence, Molecular characterization, and assessment of zoonotic risk of Cryptosporidium spp., Giardia duodenalis, and Enterocytozoon bieneusi in pigs in Henan, Central China. Journal of Eukaryotic Microbiology, 65, 893-901.

Cite this article as: Jing B, Zhang Y, Xu C, Li D, Xing J, Tao D, Zhang L, Qi M \& Wang H. 2019. Detection and genetic characterization of Giardia duodenalis in pigs from large-scale farms in Xinjiang, China. Parasite 26, 53. 
Reviews, articles and short notes may be submitted. Fields include, but are not limited to: general, medical and veterinary parasitology; morphology, including ultrastructure; parasite systematics, including entomology, acarology, helminthology and protistology, and molecular analyses; molecular biology and biochemistry; immunology of parasitic diseases; host-parasite relationships; ecology and life history of parasites; epidemiology; therapeutics; new diagnostic tools.

All papers in Parasite are published in English. Manuscripts should have a broad interest and must not have been published or submitted elsewhere. No limit is imposed on the length of manuscripts.

Parasite (open-access) continues Parasite (print and online editions, 1994-2012) and Annales de Parasitologie Humaine et Comparée (1923-1993) and is the official journal of the Société Française de Parasitologie. 